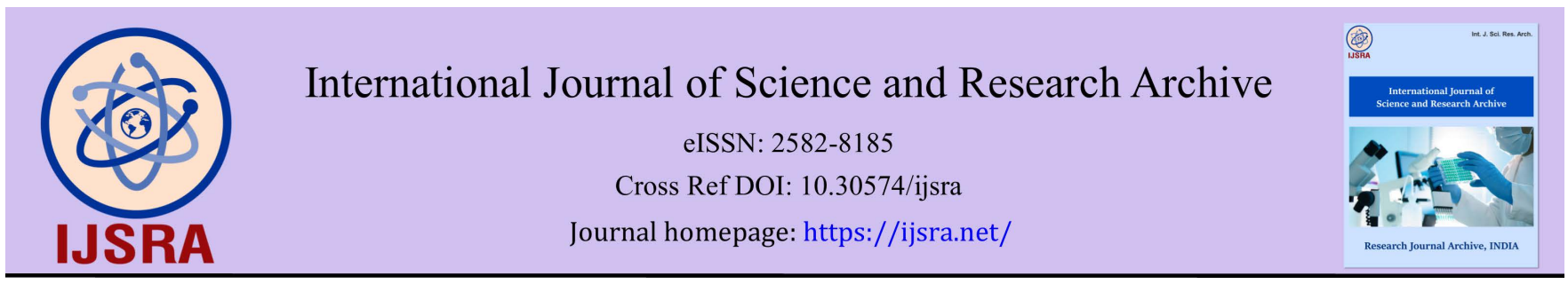

(RESEARCH ARTICLE)

Check for updates

\title{
Detailed analysis of different risk factors of cervical cancer including HPV infection at different stages of follow up of squamous intraepithelial lesions of cervix (SIL) in rural women
}

\author{
Jata Shanker Misra ${ }^{1, *}$, Anand Narain Srivastava ${ }^{2}$ and Shivani Singh ${ }^{1}$ \\ ${ }^{1}$ Department of Pathology, Era's Lucknow Medical College and Hospital, Era University, Lucknow, India. \\ ${ }^{2}$ Era's Lucknow Medical College and Hospital, Era University, Lucknow, India.
}

International Journal of Science and Research Archive, 2021, 03(01), 009-018

Publication history: Received on 25 May 2021; revised on 04 July 2021; accepted on 08 July 2021

Article DOI: https://doi.org/10.30574/ijsra.2021.3.1.0091

\begin{abstract}
Background: As situation regarding carcinoma cervix is still alarming in rural population of India, the management of HPV infection and other risk factors contributing to the development of cervical cancer might play a great role in checking the incidence of the disease.

Methods: Rural cervical cancer screening is in progress since May 2013 in the western rural region of Lucknow through camp approach and till date, follow up is available in 264 of the totals 498 Squamous Intraepithelial Lesions of Cervix (SIL) showing regression (204) and persistence of the lesions (60). The risk factors including HPV infection have been studied in detail at different stages of follow up in these two groups.
\end{abstract}

Results: Number of risk factors as obvious showed decline in the regressed cases with subsequent follow up which was lacking in the persistent group. Individually, young age factor showed decline with subsequent follow up while multiparity has been found prominent risk factors in both the groups at all stages of follow up. It was seen that the regression rate was high in women above the age of 30 years with multiparity. The decrease in number of vaginal discharge and erosion cervix cases was also found associated with regression of SIL.

Conclusion: The risk factors can predict the biological behavior of SIL towards the progression or regression of the lesions and lead to the better management of any cancer screening program. This will also reduce the follow up burden and treatment costs and will thus enhance the overall acceptability at rural level.

Keywords: Risk factors of cervical cancer; HPV infection; SIL; Regression; Persistence of the lesions

\section{Introduction}

Cervical cancer is a preventable disease and though its incidence has declined in urban population but the situation is still alarming in rural India. This is because that most of the rural population are illiterate and financially weak and are not aware of personal genital hygiene [1]. The carcinoma cervix develops through its pre-invasive phase called squamous intraepithelial lesions of cervix (SIL) but it is unable to predict behavior of these lesions for regressive or progressive tendency. Though the sufficient documentation has proved HPV infection as main risk factor associated with the development of the disease but it is not the sufficient cause of cancer initiation and progression [2]. The other factors such as age and parity are also likely involved in the cancer development [3] [4].

${ }^{*}$ Corresponding author: Jata Shanker Misra

Department of Pathology, Era's Lucknow Medical College and Hospital, Era University, Lucknow, India.

Copyright $(2021$ Author(s) retain the copyright of this article. This article is published under the terms of the Creative Commons Attribution Liscense 4.0. 
Many authors have suggested other risk factors responsible for the behavior of SIL but mostly they pertain to the urban conditions. Promiscuity is very rare in rural women which have been suggested as probable risk factor in the urban women [5]. The use of hormonal and copper IUD contraceptives are practiced for birth control in urban areas has also been associated with development of cervical cancer but are rarely adopted by the rural women [6]. Smoking has also been suggested as one of the co-factors but this habit is mostly related to the urban women and is rare in the rural women [7]. Other environmental risk factors like socioeconomic status and nutrition have also been suggested [8] [9]. Most of the rural women are illiterate and have poor economic status and hence they take mostly a low fat diet as they cannot afford fat and protein rich meals due to poverty.

Rural cervical cancer screening is in progress in the western area of Lucknow since May 2013 and till date, a total of 2949 women have been cytologically examined attending camps organized for the screening purpose. A total of 498 women have been cytologically diagnosed harboring SIL. Of these, 23 were high risk SIL (HSIL) while remaining 475 were low grade SIL (LSIL). Cytological follow up was available in 264 of these 498 SIL cases after periods ranging from 1 to 4 years and the regression of SIL was seen in 204 and persistence of SIL in the remaining 60 cases (including 3 cases of progression from LSIL to HSIL). Follow up was available in only 11 of the 23 HSIL cases. HPV-DNA testing was done in the 101 of the 204 regressed cases and HPV positivity was seen in only 8 cases and the HPV was negative in the remaining 93 cases. Similarly, HPV-DNA testing was also done in 30 of the 60 persistent SIL cases including 2 progression cases and HPV was found positive in only 10 cases (including 2 progression cases) while remaining 20 cases were HPV- negative.

A second follow up was available in 42 of the 60 cases showing persistence of SIL. In the 19 cases, the SIL has regressed to normal and in the remaining 23, the lesion persisted. A second follow up is still to be done in the remaining 18 of the 60 persistence cases. A third follow up was available in 9 of the 23 persistent cases seen on the second follow up and the lesion was found to have regressed to normal in all 9.

\subsection{A detailed analysis of following parameters in the above defined groups of SIL at the first, second and third follow up was done -}

- Total period of follow up

- Number of risk factors complained by the women of the two groups(group A consisting of HPV-negative cases and in whom HPV was not done) and (group B comprising of HPV- positive cases).

- Individual risk factors complained by the women of the two groups.

- Table 1 Risk factors associated with regression of the SIL in Group A cases

\begin{tabular}{|c|c|c|c|c|}
\hline $\begin{array}{c}\text { No. of risk } \\
\text { factors }\end{array}$ & $\begin{array}{c}\text { Initial smears } \\
\text { (204) }\end{array}$ & $\begin{array}{c}\text { First follow up } \\
\text { (196) }\end{array}$ & $\begin{array}{c}\text { Second follow up } \\
\text { (18) }\end{array}$ & $\begin{array}{c}\text { Third follow up } \\
\text { (8) }\end{array}$ \\
\hline 0 & 4 & 5 & 10 & 1 \\
\hline 1 & 39 & 71 & 4 & 1 \\
\hline 2 & 65 & 109 & 3 & \\
\hline 3 & 9 & 11 & & $3(37.5 \%)$ \\
\hline 4 & $129(63.2 \%)$ & $98(50.1 \%)$ & $8(44.4 \%)$ & $5(62.5 \%)$ \\
\hline $\begin{array}{l}\text { Individual } \\
\text { risk factors }\end{array}$ & $147(72.1 \%)$ & $143(72.9 \%)$ & $14(77.7 \%)$ & \\
\hline $\begin{array}{l}\text { Young age } \\
(21-40 \text { yrs })\end{array}$ & $65(31.8 \%)$ & $36(18.3 \%)$ & $3(16.6 \%)$ & \\
\hline Multiparity & $23(11.2 \%)$ & $1(0.5 \%)$ & & \\
\hline $\begin{array}{l}\text { Vaginal } \\
\text { discharge }\end{array}$ & & & & \\
\hline $\begin{array}{l}\text { Erosion } \\
\text { cervix }\end{array}$ & & & & \\
\hline
\end{tabular}


The risk factors at the following stages of follow up of SIL cases have been recorded in the two groups -

- Follow up of 264 SIL cases who showed regression on the first follow up in 204 cases and persistence in 60 cases.

$>$ Risk factors were studied in 204 SIL cases who showed regression of the SIL both at the time of initial smear examination and at their follow up.

$>$ Similarly, risk factors were studied in 60persistent SIL cases at the time of initial smear examination and their follow up.

- Regressionof SIL in 19 cases out of 60 persistent cases seen on second follow up.

- The persistence of SIL in 23 of the 60 persistent cases seen on the second follow up.

- Regressionof SIL in 9 cases on the third follow up available in the 23 persistent SIL cases.

The detailed data obtained on the analysis of the different risk factors including HPV infection are presented in this communication.

Table 2 Risk factors associated with regression of SIL in HPV positive cases

\begin{tabular}{|c|c|c|c|}
\hline No. of risk factors & $\begin{array}{c}\text { First follow up } \\
\text { (8 cases) }\end{array}$ & $\begin{array}{c}\text { Second follow up } \\
\text { (1 case) }\end{array}$ & $\begin{array}{c}\text { Third follow up } \\
\text { (1 case) }\end{array}$ \\
\hline 0 & 1 & - & - \\
\hline 1 & 4 & - & - \\
\hline 2 & 3 & 1 & - \\
\hline 3 & - & - & $1(100 \%)$ \\
\hline $\begin{array}{l}\text { Individual risk } \\
\text { factors }\end{array}$ & & & $1(100 \%)$ \\
\hline $\begin{array}{l}\text { Young age } \\
(21-40 \text { yrs) }\end{array}$ & $6(75 \%)$ & $1(100 \%)$ & - \\
\hline Multiparity & $4(50 \%)$ & - & - \\
\hline Vaginal discharge & - & - & $1(100 \%)$ \\
\hline Erosion cervix & - & & \\
\hline
\end{tabular}

Table 3 Risk factors associated with persistence of SIL in Group A cases

\begin{tabular}{|c|c|c|c|}
\hline No. of risk factors & $\begin{array}{c}\text { Initial smears } \\
\text { (60 women) }\end{array}$ & $\begin{array}{c}\text { First follow up } \\
\text { (50 women) }\end{array}$ & $\begin{array}{c}\text { Second follow up } \\
\text { (17 cases) }\end{array}$ \\
\hline 0 & 1 & 3 & 1 \\
\hline 1 & 10 & 16 & 5 \\
\hline 2 & 21 & 31 & 10 \\
\hline 3 & 23 & 9 & - \\
\hline 4 & 5 & 1 & $11(61.1 \%)$ \\
\hline Individual risk factors & & & $10(55.5 \%)$ \\
\hline Young age (21-40 yrs) & $50(83.3 \%)$ & $35(70 \%)$ & $2(11.1 \%)$ \\
\hline Multiparity & $48(80 \%)$ & $42(84 \%)$ & - \\
\hline Vaginal discharge & $33(55 \%)$ & $12(24 \%)$ & \\
\hline Erosion cervix & $17(28.3 \%)$ & $8(16 \%)$ & \\
\hline
\end{tabular}


Table 4 Risk factors associated with persistence of SIL in HPV positive cases

\begin{tabular}{|c|c|c|}
\hline No. of risk factors & $\begin{array}{c}\text { First follow up } \\
\text { (10 cases) }\end{array}$ & $\begin{array}{c}\text { Second follow up } \\
\text { (6 cases) }\end{array}$ \\
\hline 0 & - & - \\
\hline 1 & 4 & 4 \\
\hline 2 & 6 & - \\
\hline 3 & - & - \\
\hline 4 & - & $4(66.6 \%)$ \\
\hline Individual risk factors & $7(70 \%)$ & $4(66.6 \%)$ \\
\hline Young age (21-40 yrs) & $6(60 \%)$ & - \\
\hline Multiparity & $1(10 \%)$ & - \\
\hline Vaginal discharge & - & 2 \\
\hline Erosion cervix & & \\
\hline
\end{tabular}

\section{Material and methods}

Rural cervical cancer screening was initiated in May 2013 under the auspices of Era's Lucknow Medical College and Hospital, Lucknow through camp approach and till February 2021, a total of 186 camps were organized through proper counseling and motivation of the rural women. Pap smear was collected in 2949 women out of 5682 women who attended the camps. The cervical smear was collected from the squamo- columnar junction of the cervix by the gynecologist attending the camp and was immediately fixed in absolute alcohol. The pap smears were sent to the Cytology lab of the Department of Pathology of the college where they were stained according to the Papanicalaou's technique. The smears were screened by the cytologist and the cytopathological changes observed in the smears were graded according to the revised Bethesda System of classification of 2014 [10]. All the collected data were analyzed applying chi-square test using software SPSS version 22.

\section{Results}

Cytological examination of cervical smears of 2949 women revealed SIL in 498 cases, 23 of these were HSIL and remaining 475 LSIL. Cytological follow up was possible in 264 of these 498 SIL cases (53.1\%). Regression of SIL was seen in 204 of these 264 women (77.3\%) while remaining 60 showed persistence of SIL (22.7\%). Period when the follow up smear was taken and risk factors complained by each woman at different time of follow up have been studied in detail and given below.

Here it should be mentioned that in the rural population, the marriages are performed at early age resulting into early sexual exposure and prolonged sexual activity.A high SIL rate of $17.7 \%$ was consequently seen in the young women between $21-30$ years and $17.5 \%$ in the middle aged women between $31-40$ years. The SIL rate declined to $14.7 \%$ after 40 years in postmenopausal women. Hence high age after 40 years as risk factor of cervical cancer did not apply to the rural women and young age between 21-40 years was taken as high-risk age for analysis. Further it was also noticed that majority of the rural women who were undergone Pap smear examination were multiparous (68.7\%).

The other risk factors examined at different stages of follow up have been vaginal discharge (56.1\%), most common gynecological symptom complained by the rural women and showing maximum SIL rate (18.0\%) among other symptoms and erosion cervix seen on the clinical examination most common in the rural women (77\%) among the different lesions of cervix and also showing high SIL rate (20.7\%). The non-viral sexually transmitted diseases (STDs) Candida albicans and Trichomonas vaginalis were found very low in number and hence were not included in the study. 


\subsection{In 204 SIL cases who showed regression of the lesions on follow up}

The number of risk factors and individual risk factors complained by eachwoman in 204 women in whom the SIL was detected at the time of initial cytological examination are shown in Table-1. As evident from the Table-1, the maximum number of women complained two risk factors. The maximum number of women complained individual risk factors like multiparity (72.1\%) and young age (63.2\%). The vaginal discharge was also seen in 65 women (32.8\%) and erosion cervix in 23 cases $(11.2 \%)$.

HPV- DNA estimation was carried out in 101 of the 204 SIL cases when the follow up smears were taken which revealed HPV-positivity in 8 cases only(7.9\%). The remaining 93 cases were HPV- negative. The HPV estimation could not be done in 103 of the 204 cases. For analysis of follow up period and risk factors, two groups were formed - group A of 196 women comprising of 93 HPV- negative cases and 103 in whom HPV testing was not done and group B comprising of 8 HPV- positive cases.

The period of follow up when the regression of SIL was seen in the two groups are shown in Table-5-

Table 5 Period of follow up in regression cases

\begin{tabular}{|c|c|c|}
\hline Period of follow up & Group A (196 women) & Group B (8 cases) \\
\hline 1 year & $19(9.6 \%)$ & - \\
\hline 2 years & $151(77.1 \%)$ & $5(62.5 \%)$ \\
\hline 3 years & $6(3.1 \%)$ & $3(37.5 \%)$ \\
\hline 4 years & $8(4.1 \%)$ & - \\
\hline 5 years & $7(3.5 \%)$ & - \\
\hline 6 years & $3(1.5 \%)$ & - \\
\hline 7 years & $2(1.1 \%)$ & - \\
\hline
\end{tabular}

The follow up period ranged from 1-7 years in group A and maximum number of women were followed after 2 years (151-77.1\%). The 8 HPV-positive cases of group B were followed after 2 years ( 5 cases) and 3 years ( 3 cases). It appears that the virus infection becomes cleared before 2-3 years in these $8 \mathrm{HPV}$ positive cases resulting in the regression of the SIL.

As already mentioned, all the 204 SIL cases showed regression of the lesion on the follow up. The number of risk factors and individual risk factors complained by each women in the two groups (group A and B) have been given separately in Table- 1 and Table- 2 . The maximum number of women in both groups A and B had two risk factors. Only young age and multiparity were the common prominent risk factors seen in both the groups though decline in number of cases was noted in the age group factor from $63.2 \%$ at the time of initial examination to $51.1 \%$ at the first follow up. Only parity factor was found to have no effect on the regression of the SIL while strangely enough, vaginal discharge and erosion cervix was not seen with HPV- positivity and their low number was found in only group A cases $(18.3 \%$ and $0.5 \%$ respectively) showing drastic decline in their number after treatment than seen at the time of initial examination (32.8\% and $11.2 \%$ respectively).

In 60 women who showed persistence of SIL, risk factors seen at the time of initial examination are shown in Table-3. As expected, the maximum number of women showed 3 risk factors. Individually also, the maximum number of women showed young age (83.3\%) and multiparity (80\%). The vaginal discharge was seen in $55 \%$ and erosion cervix in $28.3 \%$ of cases.

HPV-DNA testing had been done in 30 of the 60 women showing SIL in the initial smears but showed persistence of the lesion on the follow up. The HPV- positivity was seen in 10 cases (33.3\%) while remaining 20 were HPV-negative. In the remaining 20 cases, HPV testing was not done. For studying risk factors, here also two groups were formed-group A of 50 women including 20 HPV- negative cases and 30 women in whom HPV testing was not done and group B comprising of $10 \mathrm{HPV}$ positive cases. The period of follow up in these two groups are shown in Table- 6 . 
Table 6 Period of follow up in persistent cases

\begin{tabular}{|c|c|c|}
\hline Period of follow up & Group A cases (50 cases) & Group Bcases (10 cases) \\
\hline 1 year & $10(16.6 \%)$ & $2(20 \%)$ \\
\hline 2 years & $36(72 \%)$ & $8(80 \%)$ \\
\hline 3 years & $4(6.5 \%)$ & - \\
\hline 4 years & $1(1.6 \%)$ & - \\
\hline 6 years & $1(1.6 \%)$ & - \\
\hline
\end{tabular}

As can be seen from the above figures, the maximum numbers of follow up smears were taken after 2 years of initial examination in both the groups. It appears that the virus was intact during this period in all the 10 HPV positive cases as shown by the persistence of SIL. The findings of risk factors in these two groups are shown in Table- 3 and Table - 4 . The maximum number of risk factors was found to be two in both the groups which declined from the 3 noticed initially. While the individual risk factors were young age and multiparity shown by the maximum number of cases in both the groups. The percentage of vaginal discharge and erosion cervix cases seen on the initial examination showed receding trend on the follow up from $55 \%$ to $24 \%$ in the cases of vaginal discharge and from $28.3 \%$ to $16 \%$ in the cases of erosion cervix and was almost negligible in HPV- positive cases.

A second follow up was available in 42 of the 60 SIL cases showing persistence on the first follow up. Of these 42,19 showed regression of the lesion on second follow up while persistence of SIL was seen in 23. The remaining 18 cases of persistent SIL are still to be followed.

In 19 persistent SIL cases who showed regression of the lesion on second follow up, HPV was done in 5 cases and in the remaining 14, this was not done. The HPV was positive in 1 case and negative in 4 cases. Total period of follow up when the regression was seen in 19 cases is given below in the two groups in Table-7 Group A comprising of 18 cases (HPVnegative 4 cases and 14 cases in whom HPV was not done) and Group B comprising of only 1 HPV positive case.

Table 7 Period of follow up in 19 persistent cases showing regression of second follow up

\begin{tabular}{|c|c|c|}
\hline Total period of follow up & Group A (18 cases) & Group B(1 cases) \\
\hline 2 year & 1 & - \\
\hline 4 years & 5 & 1 \\
\hline 5 years & 4 & - \\
\hline 6 years & 4 & - \\
\hline 7 years & 4 & - \\
\hline
\end{tabular}

The maximum numbers of cases were followed after 4 years in both the groups. It appears that the virus in the one positive case was not present till 4 years as shown by the regression of the lesion and might have cleared in between 1 to 4 years.

The number of risk factors and individual risk factors are shown in Table-1 and Table- 2. It was seen that majority of women in group A showed decline in the number of risk factors from 2 to 1 while similar number of risk factors (2) were present in only $1 \mathrm{HPV}$ positive case (group B). Similarly young age and multiparity were the only individual prominent risk factors shown by the group A cases and the only 1 HPV positive case (group B) but the percentage of age factor showed decline with increase in the follow up. Similar trend was also seen with vaginal discharge while no case of erosion cervix was seen.

A total of 23 cases showing persistence of SIL on first follow up also showed continuity of the persistence on the second follow up. HPV testing was done in 14 of these 23 SIL cases which revealed HPV positivity in 6 and HPV was negative in the remaining 8. In 9 of the 23 cases, HPV testing was not done. The total period of follow up in these 23 cases comprising 
of group A of 17 women ( 8 HPV negative and 9 in whom HPV was not done) and group B of 6 HPV positive cases are shown in Table-8.

Table 8 Period of follow up in 23 persistent cases on second follow up

\begin{tabular}{|c|c|c|}
\hline Total period of follow up & Group A (17 cases) & Group B (6 cases) \\
\hline 2 year & 3 & 2 \\
\hline 3 years & 4 & - \\
\hline 4 years & 7 & 2 \\
\hline 5 years & 2 & 2 \\
\hline 6 years & 1 & - \\
\hline
\end{tabular}

The maximum number of women were followed after 4 years in Group A cases while 2 each of the 6 HPV positive cases of Group B were seen at 2, 4 and 5 years.

Number of risk factors and individual risk factors shown by each woman in 23 women at their second follow up are shown in Table- 3 and Table -4. As evident from the Table, there was no difference in number of risk factors shown by group A and B cases on first and second follow up as this was found to be 2 at both stages of follow up. Similarly young age and multiparity was shown by maximum number of women at the second follow up. Further it was observed that the vaginal discharge cases also showed decline in the number of cases at the second follow up than those found at the first follow up (11.1\% from 24\%). No case of erosion cervix was seen at the second follow up. In group A cases in whom HPV was negative, it appears that risk factors like age and parity played crucial role in the persistence of SIL.

A third follow up was available in 9 of the 23 persistent SIL cases seen on the second follow up. HPV testing was done in 6 of these 9 while in the remaining 3, HPV testing could not be done.HPV was positive in 1 case and negative in the remaining 5. Total period of follow up in these 9 cases in group A ( 8 cases) and group B (1 case) is given in Table- 9 .

Table 9 Period of follow up in 9 persistent cases showing regression on third follow up

\begin{tabular}{|c|c|c|}
\hline Total period of follow up & Group A (8 cases) & Group B(1 cases) \\
\hline 3 years & 1 & - \\
\hline 5 years & 5 & 1 \\
\hline 6 years & 2 & - \\
\hline
\end{tabular}

Maximum numbers of cases were followed after 5 years in Group A and the only 1 HPV-positive case.

Number of risk factors and individual risk factor shown by each women in 9 cases are shown in Table-1 and Table- 2 . The maximum number of risk factors in group A cases was 1 while the only 1 positive case had two risk factors. Here it should be emphasized that number of risk factors remaining 1 at the end of second and third follow up in group A cases shows that the least number of risk factors are associated with regression of the lesion. Similarly young age and multiparity was common in group A cases both at second and third follow up but this figure was $100 \%$ in the case of group B ( $1 \mathrm{HPV}$ positive case). The age factor continued to show decline to $37.5 \%$ with regression of SIL in group A cases.

The statistical analysis was carried out to see the trend of different risk factors at successive stages of follow up. The age risk factor which was $63.2 \%$ at the time of initial smears examination in 204 women declined to $37.5 \%$ at third follow up and the difference was statistically significant $\left(\chi^{2}=9.28 ; p=0.026\right)$. It is obvious as the some of these women have attained menopause with increasing duration of follow up which is associated with regression of SIL. The difference seen in the percentage of multiparity (72.1\%) at the time of initial examination to $62.5 \%$ at the end of third follow up was not found to be statistically significant $\left(\chi^{2}=0.69 ; \mathrm{p}=0.875\right)$ and hence multiparity appears to more prominent risk factor for development of cervical cancer. 
Other risk factors like vaginal discharge which incidence was 31.8\% at the time of initial smear examination declined after treatment to $16.6 \%$ at the second follow up and no case was seen at the third follow up. The difference in the decline of the incidence of vaginal discharge was statistically significant $\left(\chi^{2}=10.42 ; p=0.005\right)$. Similarly, the percentage of women showing erosion cervix at the time of initial examination was $11.2 \%$ and declined to $0.5 \%$ at the first follow up and no case was seen at the second and third follow up. Here also the difference in the incidence was statistically significant $\left(\chi^{2}=20.54 ; p<0.001\right)$. Hence the decline in the percentage of the cases with vaginal discharge and erosion cervix after treatment with increasing duration of follow up shows that their elimination is related to the regression of SIL.

In the HPV positive cases (10), the risk factors like age and parity showed high percentage with increase in follow up. It appears that virus clearance in these 10 cases is associated with the regression of the SIL.

The statistical analysis was also done to assess the role of different risk factors in the persistence of SIL (Table-3). In group A cases, the number of risk factors which was 3 at the time of initial examination declined to 2at the first and second follow up. As regards individual factors, the young age showed statistically insignificant difference as percentage of cases which declined from 83.3 noticed at initial examination to $61.1 \%$ at second follow up $\left(\left(\chi^{2}=3.84 ; \mathrm{p}=0.143\right)\right.$. With multiparity,a statistical significant difference was seen as the percentage of cases declined to $55.5 \%$ at the second follow upfrom $80 \%$ noticed at the time of initial examination $\left(\chi^{2}=4.91 ; p=0.086\right)$. With the vaginal discharge, the percentage declined to $11.1 \%$ at the second follow up from $55 \%$ seen initially and here, too, the difference was statistically significant $\left(\chi^{2}=11.51 ; \mathrm{p}=0.003\right)$. However, with the erosion cervix, the difference was insignificant $\left(\chi^{2}=\right.$ $2.36 ; \mathrm{p}=0.124)$.

In the HPV positive cases (Table-4), there was no decline in the percentage with any risk factors and hence the difference was statistically insignificant. No case of erosion cervix was seen.

\section{Discussion}

In the present study, following risk factors were analyzed in detail at the different stages of follow up of SIL cases - young age (21-40 years), multiparity, vaginal discharge and erosion cervix. A high SIL rate observed in the young women in the present series have also been reported by Srivastava et al, Nikumbh et al. and Rajput et al. [11-13]. The early marriage prevalent in the rural population leading to the early sexual exposure and prolonged sexual activity as advocated by us as a potential risk factor of carcinoma cervix have also been emphasized by many investigators like Iyer et al, Misra et al,Caslenda-Iniguez et al, Green et al, Dietsch et al and Kashyap et al, [14-19].

Multiparity was another prominent risk factor related to the carcinoma cervix and in the present series, this was most pronounced as majority of women opting for Pap test were multiparous (63.7\%). Multiparity as risk factor of carcinoma cervix has also been reported in their rural findings by Rajput et al., Das Gupta et al and Ray Chaudhary et al [20][21].

The vaginal discharge has also been commonly complained by rural women as gynecological symptom and this may be related to the poor genital hygiene due to illiteracy. Ray Chaudhary et al, Thulaseedharan et al.and Zhang et al have also stressed illiteracy as contributory risk factors of cervical cancer in the rural women [22][23]. Erosion cervix was also seen in the present series showing high SIL rate. Similar findings have been also reported byRajput et al and Nikumbh et al [11-13].

In the present series, 264 SIL cases have been followed showing regression of the lesions in 204 and persistence of SIL in the remaining 60. A second follow up was available in 42 of the 60 persistent cases, 19 of these showing regression of SIL and persistence in the remaining 23. A third follow up was available in 9 of the 23 persistent cases showed regression of the SIL to normal in all 9. Therefore, we had 3 follow up stages, first and second showing both regression and persistence of SIL while third follow up showed only regression of the SIL.

The cytological regression of SIL was thus seen in 204 cases at the first follow up, in 19 persistent cases on second follow up and in 9 at the third follow up. Thus, the total number of cases showing regression of SIL was 232/264 (87.9\%). The remaining 32 cases showed persistence of SIL (18 at the first follow up and 14 at the second follow up) and all of them are still to be followed.

As regards regression of the SIL cases, though the number of risk factors was two at the first follow up but declined to one at the second and third follow up. Hence there was some relationship between low numbers of risk factors with regression of SIL and it is obvious because the process of regression is accelerated when the risk factors are minimal. 
However, as expected this association was not seen with persistence of SIL as number of risk factors declined from 3 observed at the initial examination to 2 at the first and second follow up.

As regards the individual risk factors, in the regressed cases as well as those showing persistence of SIL, the young age and multiparity were the common prominent risk factors at all the stages of follow up. However, it was seen that the women above the age of 30 years and having multiparity have high regression rate with than younger women below 30 years and bearing 1 or 2 children or nulliparous. Many authors have also found regression rate higher in women of old age than young ones [24][25][26][27]. In the regressed cases, vaginal discharge and erosion cervix was also seen at the time of initial examination but declined at the first and second follow up and none of them were seen at the third follow up. Strangely enough, these two risk factors were though seen at the time of initial examination in the persistent cases but declined to more than $50 \%$ at the first follow up and were very low at the second follow up.

In the persistent cases, the individual risk factors were high but showed decline with increasing follow up though to not that magnitude as seen in the regression cases. Further it was seen that the SIL regressed in 10 HPV positive cases. It appears that the virus clearance and regression of SIL occurred at the same time within 1 to 2 years. Molano et al have also opined similar hypothesis.

\section{Conclusion}

The risk factors can be utilized in predicting regression or persistence of SIL as well as duration of SIL leading to the development of carcinoma cervix. This will lead to the reduction in the progression of the lesions, reduce the follow up burden and treatment costs and thus will increase the overall acceptability of any cervical cancer screening program in the rural India.

\section{Compliance with ethical standards}

\section{Acknowledgments}

The authors thank village Heads of Kakori, Malihabad and Mall blocks of west Lucknow for helping in organizing camps for cervical cancer screening.

\section{Disclosure of conflict of interest}

The authors have no conflict of interest to declare

\section{Statement of informed consent}

Informed consent was obtained from the women who have undergone Pap smear examination on the Pap smear form as thumb impression if illiterate and signature if educated.

\section{References}

[1] Tripathi N, Kadam YR, Dhobale RV, Gore AD. Barriers for early detection of cancer amongst Indian rural women. South Asian J Cancer. 2014; 3:122-7.

[2] Bosch FX, Sanjose DS. Limitation of the evidence and areas of further research. J. Natl. Cancer Inst. Monogr. 2003;31(3):03-13.

[3] Bosch F, Munoz N, Sanjose DS, Izarzugaza I, Gilli M, Viladiu P et al. Risk factors for cervical cancer in Colombia and Spain. Int. J. Cancer. 1992;52:(5):750-58.

[4] Schiffman MH, Bauer HM, Hoover RN, Glass AG, Cadell DM, Rush BB, et al. Epidemiologic evidence showing that human papillomavirus infection causes most cervical intraepithelial neoplasia. J Natl Cancer Inst. 1993;85(12):958-64.

[5] Molano M,Gonzalex M, Gamboa O, Ortiz N, Luna J, Hernandez G, et al. Determinants of LSIL regression in women from a Colombian cohort. Rev. Colomb Cancerol. 2010;14(4): 199-209.

[6] IARC. Hormonal contraception and post-menopausal hormonal therapy. IARC monographs on the evaluation of carcinogenic risks to humans, Vol. 72. Lyon:IARC. 1999.

[7] Winkelstein W Jr. Smoking and cancer of the uterine cervix: Hypothesis. Am J Epidemiol. 1977;106(4):257-59. 
[8] de Sanjose S, Bosch FX, Muñoz N, Shah K. Social differences in sexual behavior and cervical cancer. In: Kogevinas M, Pearce N, Susser M, et al, eds. Social inequalities and cancer. Lyon: IARC Scientific Publications. 1997;138:30917.

[9] Potischman L, Brinton LA. Nutrition and cervical neoplasia. Cancer Causes Control. 1996;7:113-26.

[10] Nayar R, Wilbur DC. The pap test and bethesda 2014. Acta Cytologica. 2015;59:121-32.

[11] Srivastava M, Srivastava OP, Jaiswal SS. Pattern of cervical smear cytology in rural medical college. Pravera Med Rev. 2011;3(1):04-08.

[12] Nikumbh DB, Nikumbh RD, Dombale VD, Jagtap SV, Desai SR. Cervicovaginal cytology: Clinicopathological and social aspect of cervical cancer screening in Rural Maharashtra, India. Int J Health Sci Res. 2012;1(2):125-32.

[13] Rajput N, Verma YS, Ahirwar G. Detection of abnormal cervical cytology by Pap smear and comparison between rural and urban women. J Evol Med Dental Sci. 2013;2(41):7923-30.

[14] Iyer SS, Shah SK. Colposcopy as diagnostic aid in unhealthy cervix. J Obstet Gynaecol India. 1981;31:495-98.

[15] Misra JS, Srivastava AN, Zaidi ZH. Cervical cytological changes associated with prolonged sexual exposure due to early marriage in rural India. J Clin Diag Res. 2020;14(1):EC06-10.

[16] Caslaneda-Iniguez MS, Toledo CR. Risk factors for cervico-uterine cancer in women in Zacatecas. Salud Publica Mex. 1998;40(4):330-38.

[17] Green J, Berrington de GA, Sweetland S, Beral V, Chilvers C, Crossley B, et al. Risk factors for adenocarcinoma and squamous cell carcinoma of the cervix in women aged 20-44 years: The UK national case-control study of cervical cancer. Br J Cancer. 2003;89(11):2078-86.

[18] Dietsch E, Gibb H, FrancisK. Abnormal Pap test results and the rurality factor. Aust J Rural Health. 2003;11(2):5057.

[19] Kashyap N, Krishnan N, Kaur S, Ghai S. Risk factors of cervical cancer: A casecontrol study. Asia Pac J Oncol Nursing. 2019;6(3):308-14.

[20] Das Gupta A, Naskar NN, Ram R, Deb S. A community based study of the prevalence of risk factor of carcinoma cervix in married women of rural area of West Bengal. Ind. J Community Med. 2012;27(1):36-39.

[21] Raychaudhari S, Mandal S. Sociodemographic and behavioural risk factors for cervical cancer and knowledge, attitude and practice in rural and urban areas of North Bengal, India. Asian Pac J Cancer Prev. 2012;13(4):109296.

[22] Zhang ZF, Parkin DM, Yu SZ, Esteve J, Yang XZ. Risk factors for cancer of the cervix in a rural Chinese population. Int J Cancer. 1989;43(5):762-67.

[23] Thulaseedharan JV, Malila N, Haka AM, Esmy PO, Cherian M, Swaminathan R, et al. Sociodemographic and reproductive risk factors for cervical cancerA large prospective cohort study from rural India. Asian Pacific J Cancer Prev. 2012;13:2991-95.

[24] Edelman M, Fox AS, Alderman EM, Neal W, Shapiro A, Silver EJ, et al. Cervical Papanicolaou smear abnormalities in inner city Bronx adolescents: prevalence, progression, and immune modifiers. Cancer. 1999;87(4):184-9.

[25] Kirby AJ, Spiegelhalter DJ, Day NE, Fenton L, Swanson K, Mann EM, et al. Conservative treatment of mild/moderate cervical dyskaryosis: long-term outcome. Lancet. 1992;339(8797):828-31.

[26] Montz FJ, Monk BJ, Fowler JM, Nguyen L. Natural history of the minimally abnormal Papanicolaou smear. Obstet Gynecol. 1992;80(3 Pt 1):385-8.

[27] Nasiell K, Nasiell M, Va lavinková V. Behavior of moderate cervical dysplasia during long-term follow-up. Obstet Gynecol. 1983;61(5):609-14. 